\title{
Towards an Ability to Direct College Students to an Appropriately Paced Introductory Computer Science Course
}

\author{
James Heliotis \\ jeh@cs.rit.edu \\ Rochester Institute of Technology \\ Mohsen Dorodchi \\ Mohsen.Dorodchi@uncc.edu \\ University of North Carolina
}

\author{
Leo C. Ureel II \\ ureel@mtu.edu \\ Michigan Technological University \\ Victoria Eisele \\ Victoria.eisele@frontrange.edu \\ Front Range Community College \\ Ethel Tshukudu \\ 2371984T@student.gla.ac.uk \\ University of Glasgow
}

\author{
Mireilla Bikanga Ada \\ Mireilla.BikangaAda@glasgow.ac.uk \\ University of Glasgow \\ Megan E. Lutz \\ mlutz@uga.edu \\ University of Georgia
}

\begin{abstract}
We propose a working group to investigate methods of proper placement of university entrance-level students into introductory computer science courses. The main issues are the following.

(1) The ability to predict skill in the absence of prior experience

(2) The value of programming language neutrality in an assessment instrument

(3) Stigma and other perception issues associated with students' performance, especially among groups underrepresented in computer science

(4) The impact or potential impact on underrepresented populations (minorities, those with lower socioeconomic status)

(5) The outcomes/satisfaction/retention metrics in the major of the paced/tracked students compared to those in one-sizefits-all introductory classes
\end{abstract}

We perceive the current advanced placement exams offered by organizations such as The College Board to be inadequate for our purposes because they are language specific and they test the results of taking a standardized course. Their exams are not intended to determine whether or not a student who has not been exposed to computing or who has been exposed to a different computing paradigm or language would be able to grasp completely new concepts quickly.

Members of the group will collect evidence-based research on freshman college student readiness, the utility of so-called "placement" and "entrance" exams, and actual exams employed by universities.

Admission to the group has been determined largely by the documented ability of the applicant to collect such information and/or to be able to contribute to the anticipated intense debates that will be part of the work.

Permission to make digital or hard copies of part or all of this work for personal or classroom use is granted without fee provided that copies are not made or distributed for profit or commercial advantage and that copies bear this notice and the full citation on the first page. Copyrights for third-party components of this work must be honored.

For all other uses, contact the owner/author(s).

ITiCSE '19, July 15-17, 2019, Aberdeen, Scotland Uk

(c) 2019 Copyright held by the owner/author(s).

ACM ISBN 978-1-4503-6301-3/19/07.

https://doi.org/10.1145/3304221.3325538

\section{CCS CONCEPTS}

- Social and professional topics $\rightarrow$ Computer science education; CS1; Student assessment.

\section{KEYWORDS}

Assessment, placement, introductory courses

\section{ACM Reference Format:}

James Heliotis, Leo C. Ureel II, Mireilla Bikanga Ada, Mohsen Dorodchi, Victoria Eisele, Megan E. Lutz, and Ethel Tshukudu. 2019. Towards an Ability to Direct College Students to an Appropriately Paced Introductory Computer Science Course. In Innovation and Technology in Computer Science Education (ITiCSE '19), fuly 15-17, 2019, Aberdeen, Scotland Uk. ACM, New York, NY, USA, 2 pages. https://doi.org/10.1145/3304221.3325538

\section{INTRODUCTION}

Worldwide, computer science (CS) as a discipline is in a transition period as far as education is concerned. In adult life, in personal pursuits, but especially in careers, some level of familiarity with computational thinking and the ability to apply computer-based methods to analytical problems is becoming very widespread. But in the educational sphere, computer science and its related disciplines are still not universally considered as a pillar of educational systems, as are the humanities, the arts, mathematics, and the natural sciences.

As a result, there are still many students who have not been exposed to computing by the time they finish their secondary education. This causes two problems. The first is that unfamiliarity makes it difficult for an individual to make an experience-informed decision on a career path. The second problem is that, unlike in most other fields, the student and the higher educational institution have no data with which an initial course plan can be constructed.

This working group will be mostly concerned with the second problem. While some find evidence to support the notion that different students may need different forms of instruction [1][4][5], it should be noted that there is an opposing claim, also backed by evidence, that there is no need to start students of different abilities in different courses; that there are ways to design and deliver CS course material in such a way as to neutralize those differences and help everyone succeed. [2] [3] But given the pace at 
which some institutions prefer that their introductory CS courses proceed, and that placement exam results, offered by organizations such as The College Board and by individual institutions, are a completely normal part of course planning, this working group will be looking for an alternative placement approach for CS that also uses assessment.

\section{ACTIVITIES AND EXPECTATIONS}

Our working group approach is organized around four activities.

\subsection{Capture a variety of perspectives on placement issues in introductory CS.}

Participants will develop position papers describing their own perspectives of incoming student readiness, factors that affect student performance, and approaches to placement into introductory computer science courses. These papers will be synthesized by the workshop organizers prior to the working group meeting.

\subsection{Collect evidence-based research on freshman college student readiness.}

Participants will all be asked to contribute to the body of knowledge with which the group will work. Contributions should be in the form of published papers about well-run studies, plus other forms of preliminary data such as grades collected as various approaches were tried. The data can come from the participants' own work or from literature searches they perform. Publications contributed may very well include contrary positions, wherein researchers have recommended against assessment and any resulting classification of an incoming student cohort.

We perceive the current advanced placement exams offered by organizations such as The College Board to be inadequate for our purposes because they are either language specific, or intended to introduce computing in a general sense, and they test the results of taking a standardized course. Their exams are not intended to determine whether or not a student who has not been exposed to computing or has been exposed to a different computing paradigm or language would be able to grasp completely new concepts quickly Furthermore, the AP CS Principles test is only two years old and too new for us to adequately predict how students will perform at the college level.

\subsection{Classify}

During the working group meeting, participants will attempt to categorize approaches along different dimensions. Although these dimensions will be firmed up later, here are some examples.

- Assessment instrument content: is it a previous experience questionnaire, a test of certain mathematical skills, the understanding of algorithms in pseudo code, or problems expressed in a programming language designed for the test?

- Demographics: is there anything about the student population involved that should be noted?

- Delivery method: distance, in-person handwritten, or inperson but still on-line and perhaps auto-graded? And when? (well before / before / after arrival on campus)
- Strength of results: how convincing are the results in terms of conventional experimental standards and statistical analysis?

\subsection{Construct a reference model that relates the various approaches along various dimensions; conclusions if possible.}

A reference model will be developed during the working group meeting that will attempt to collect information from the classification exercise into a matrix-like form that will help others who are considering assessment for this purpose. In addition, we will have separate discussions focusing on the studies which discuss the relationship of proper placements with more successful students as far as time to graduation, readiness for industry, and overall degree satisfaction by students.

\subsection{Report}

Besides a concluding single report, the goal will be to create an easily navigable web site with the work products of the above activities that will also enable for post-conference work.

\section{GROUP LEADERS}

James Heliotis - James E. Heliotis is a professor in the Computer Science Department at Rochester Institute of Technology where he has taught for over 35 years. Dr. Heliotis has been a steady instructor and frequent coordinator of the first-year courses for the approximately $500 \mathrm{CS}$, SE, and other majors who take the courses each year. In this capacity he has been involved in several internally and externally funded projects to improve and re-invent the introductory CS curriculum over the years.

Leo Ureel - Leo C. Ureel II is a lecturer in Computer Science at Michigan Technological University. Mr. Ureel teaches CS1 and CS2 courses, primarily to first year students. In these courses, he works to broaden the students' views of computing, ground them in a programming language, and teach them problem solving skills.

\section{ACKNOWLEDGMENTS}

This work is partly supported by the National Science Foundation under Grant No. 1820862. Mohsen Dorodchi is the corresponding author.

\section{REFERENCES}

[1] Glen Archer, Leonard Bohmann, Allison Carter, Christopher Cischke, Linda M Ott, and Leo Ureel. 2016. Understanding similarities and differences in students across first-year computing majors. In Frontiers in Education Conference (FIE), 2016 IEEE. IEEE, 1-8.

[2] Ivona Bezakova, James Heliotis, and Sean Strout. 2014. On the efficacy of board game strategy development as a first-year CS project. In Proceedings of the 45th ACM technical symposium on Computer science education. ACM, Atlanta, GA, USA, 283-288.

[3] Michael E Caspersen, Kasper Dalgaard Larsen, and Jens Bennedsen. 2007. Mental models and programming aptitude. ACM SIGCSE Bulletin 39, 3 (2007), 206-210.

[4] Lisa L Lacher, Albert Jiang, Yu Zhang, and Mark C Lewis. 2017. Aptitude and previous experience in cs1 classes. In Proceedings of the International Conference on Frontiers in Education: Computer Science and Computer Engineering (FECS). The Steering Committee of The World Congress in Computer Science, Computer Engineering and Applied Computing (WorldComp), 87-95.

[5] Linda Ott, Briana Bettin, and Leo Ureel. 2018. The impact of placement in introductory computer science courses on student persistence in a computing major. In Proceedings of the 23rd Annual ACM Conference on Innovation and Technology in Computer Science Education. ACM, 296-301. 